\title{
The potential use of extended criteria donors and eligible recipients in liver transplantation for unresectable colorectal liver metastases in Central Sweden
}

\author{
Christina Villard ${ }^{1}$, Joakim Westman ${ }^{2}$, Jonas Frank ${ }^{2}$, Oystein Jynge ${ }^{3}$, Ernesto Sparrelid ${ }^{1,4 \#}$, Carl Jorns ${ }^{3,4 \#}$ \\ ${ }^{1}$ Department of Cancer, Division of Upper GI, Karolinska University Hospital, Stockholm, Sweden; ${ }^{2}$ Karolinska Institutet, Stockholm, Sweden; \\ ${ }^{3}$ Department of Transplantation Surgery, Karolinska University Hospital, Stockholm, Sweden; ${ }^{4}$ Department of Clinical Science, Intervention and \\ Technology, Karolinska Institutet, Stockholm, Sweden \\ Contributions: (I) Conception and design: C Villard, E Sparrelid, C Jorns; (II) Administrative support: C Villard, J Westman, J Frank, O Jynge; (III) \\ Provision of study material or patients: C Villard, E Sparrelid, C Jorns; (IV) Collection and assembly of data: C Villard, J Westman, J Frank, O \\ Jynge; (V) Data analysis and interpretation: C Villard, J Westman, E Sparrelid, C Jorns; (VI) Manuscript writing: All authors; (VII) Final approval of \\ manuscript: All authors. \\ "These authors shared the last author. \\ Correspondence to: Christina Villard, MD, PhD. Department of Cancer, Division of Upper GI, K42, Karolinska University Hospital, 14186 \\ Stockholm, Sweden. Email: christina.villard@ki.se.
}

Background: Unresectable colorectal liver metastases (CRLM) is a condition with poor prognosis. A recent treatment alternative improving survival in patients with unresectable CRLM, has emerged with the introduction of liver transplantation (LT), yet not uncontroversial with the current organ shortage. This study aimed to retrospectively investigate the potential of declined donors with acceptable risk as liver graft donors and patients with unresectable CRLM as potential recipients.

Methods: All declined donors in central Sweden and all patients with CRLM discussed at multidisciplinary team conference at Karolinska University Hospital, January 2013-October 2018, were identified. Donors were classified according to the European Committee Guide to the quality and safety of organs for transplantation and potential recipients were evaluated by selection criteria, based on studies on the Norwegian Secondary Cancer study database.

Results: Out of 1,462 evaluated potential donors, 62 (2.7 pmp) donors were identified, corresponding to $6-18 \%$ of the utilized donor pool. Out of 1,008 included patients with CRLM, 25 (2.1 pmp) potential recipients were recognized. Eligibility for LT and left-sided colon cancer were favorable prognostic factors.

Conclusions: Today's donor pool could increase with the use of extended criteria donors, which is sufficient and display an acceptable risk-benefit ratio for patients with unresectable CRLM. With current selection criteria a small subset of patients with unresectable CRLM are eligible recipients. This subset of patients has a better survival compared to patients ineligible for LT.

Keywords: Colorectal cancer (CRC); extended criteria donor; unresectable colorectal liver metastases (unresectable CRLM); liver transplantation (LT)

Submitted Nov 16, 2019. Accepted for publication Mar 03, 2020.

doi: $10.21037 / \mathrm{hbsn} .2020 .03 .10$

View this article at: http://dx.doi.org/10.21037/hbsn.2020.03.10 


\section{Introduction}

The vast majority of patients with colorectal liver metastases (CRLM) are not amenable for curative resection at time for presentation $(1,2)$. Advances in chemotherapy has resulted in increased resectability rates, yet for the predominant part of patients with unresectable CRLM palliative chemotherapy remains the only treatment option, with a poor prognosis (3-7).

Recent results from the studies, based on the Norwegian Secondary Cancer (SECA) study database, evaluating liver transplantation (LT) as a treatment alternative for patients with metastatic colorectal cancer (CRC) restricted to the liver, have shown promising results with a 5 -year survival of up to $83 \%(8-10)$.

CRC yearly affects 6,000 patients in Sweden $(11,12)$. At the same time the mortality rate on the waiting list is annually $4-6 \%$, thus the potential allocation of liver grafts to metastatic CRC is controversial (13). The current shortage of organs for patients in which LT is an established treatment has led to the evaluation of extended criteria donors, with promising results (14-16). One way to expand the donor pool and meet the potential demand of adding metastatic CRC to the LT waiting list is to use marginal grafts, initially in clinical trials. The aim of this study was to retrospectively investigate the potential of declined donors with acceptable risk as liver graft donors and patients with unresectable CRLM as potential liver transplant recipients. The secondary aim of the study was to describe the potential recipients, with regards to survival and eligibility for transplantation. We present the following article in accordance with the STROBE reporting checklist (available at https://hbsn.amegroups.com/article/view/10.21037/ hbsn.2020.03.10/rc).

\section{Methods}

\section{Potential recipients}

All patients with CRLM discussed at our regional hepatobiliary multidisciplinary team (MDT) conference at the Department of Cancer, Division of Upper GI, Karolinska University Hospital from of $1^{\text {st }}$ January 2013 to $31^{\text {st }}$ of September 2018, were evaluated. The region of interest had 2,344,124 residents by $31^{\text {st }}$ December of 2018. In addition to patients living in the county of Stockholm approximately $25 \%$ of patients were referred for discussion at MDT conference from surrounding counties and a limited number from other countries. Patient records were analyzed according to a structured protocol including clinicopathological characteristics of CRLM, primary tumor, chemotherapy and survival. A CRLM was considered synchronous if diagnosed within 4 months after diagnosis of the primary tumor. CRLM were determined irresectable if criteria of resectability could not be met: to remove all macroscopic disease with enough resection margin and leave enough remaining liver volume, as to ensure sufficient liver function (17). All patients in which chemotherapy had not been given previously or who were candidates for conversion and/or downstaging therapy were evaluated after treatment, i.e., had had at least two months of chemo therapy. The exclusion criteria were lack of data on clinicopathological characteristics and survival. Criteria based on the inclusion and exclusion criteria in the SECA studies were used to identify eligible candidates for LT (Table S1) $(10,18)$.

\section{Potential donors}

All declined donors in central Sweden from $1^{\text {st }}$ of January 2013 to $31^{\text {st }}$ of September 2018 were identified through the organ procurement organization (OPO) donor registry as well as The Swedish Intensive Care Registry and classified by review of medical records. Donors were categorized according to terminology recommended by the World Health Organization (WHO) and The Transplantation Society (TTS) (19). A possible donor: a patient with a devastating brain injury or lesion or a patient with circulatory failure and apparently medically suitable for organ donation. Potential donor: a person whose clinical condition was suspected to fulfill brain death criteria. Eligible donor: a person in which the diagnosis of brain death was confirmed, and there were no previously known contraindications to donation. Actual donor: a person in whom an operative incision was made with the intent of organ recovery. Utilized donor: an actual donor from whom at least one organ was transplanted (19).

The region of interest had 4,449,253 residents by $31^{\text {st }}$ December of 2017. Only donation after brain death (DBD) was included. Donors were classified according to the European Committee Guide to the quality and safety of organs for transplantation (EDQM). The inclusion and exclusion criteria are summarized in (Table S2). All 179 potential DBD donors included in the final analysis were evaluated on a case by case basis according to EDQM risk stratification for transmission of infectious and neoplastic disease. Low-to-intermediate risk donors were accepted, 
Table 1 Clinicopathological characteristics in patients with resectable and unresectable CRLM

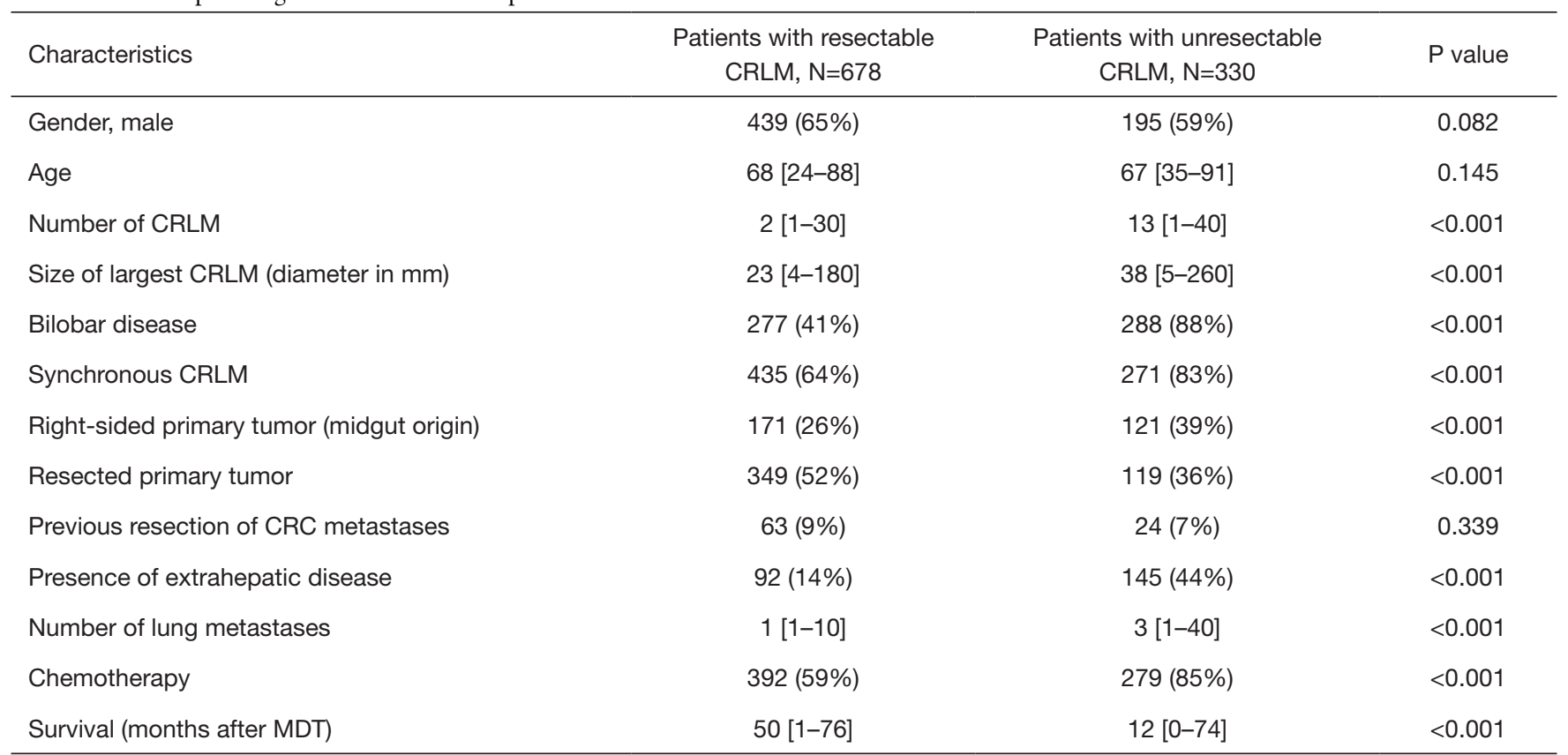

Data presented in median [min-max] for continuous variables and frequency (percent) for categorical variables. CRLM, colorectal liver metastases; CRC, colorectal cancer; MDT, multidisciplinary team.

whereas high-risk and unacceptable risk donors were excluded. In case of lack of or insufficient information about the medical history, the patient was assigned the highest risk for that specific diagnosis. Liver function was evaluated by an experienced transplant surgeon based on patient history, blood group, weight, height, age, knowledge of risk behavior and the blood function tests: INR, bilirubin, AST, ALT, GT and ALP. Liver function was considered acceptable if INR and bilirubin was within normal range and AST and ALT were less than 3 times the upper limit.

The study was conducted in accordance with the Declaration of Helsinki (as revised in 2013). The study was approved by the Regional Ethics Committee in Stockholm (NO 2018/1261-31).

\section{Statistical analysis}

Statistical analysis was performed with SPSS 23.0. ShapiroWilk test was used to test for normal distribution of data. Independent $t$-test was used for comparisons of normally distributed data and Mann-Whitney $\mathrm{U}$ test was used for data that failed the normality test. Chi square test and Fischer's exact test were used for categorical variables, normal and non-normal distributed, respectively. Overall survival
(OS) was estimated using the Kaplan Meier method and compared using Log ranks test for univariate comparisons and Cox proportional hazards regression for multivariate comparisons. Clinicopathological characteristics of the CRLM underwent a stepwise Cox regression analysis. All baseline variables were initially analyzed in a univariate Cox regression. Any variable scoring a $\mathrm{P}$ value $<0.1$ was then included in a multivariate Cox proportional hazard model. Statistical significance was assumed for $\mathrm{P}$ values $<0.05$.

\section{Results}

\section{Potential recipients}

During the study period, 1,040 patients were identified. Out of these, 1,008 patients (97\%) were included in the study. Patients were excluded due to lack of CRLM in pathology report $(\mathrm{n}=19)$, lack of information on survival, if the patients were inhabitants of foreign countries $(n=8)$, inadequate information at MDT conference $(n=6)$, occurrence of metastases with another tumor origin $(n=4)$. Twenty-five patients were determined inoperable due to other illnesses, out of which 16 patients had resectable CRLM.

Clinicopathological characteristics in patients with resectable and unresectable CRLM are summarized in 
Table 1. Patients with unresectable CRLM differed significantly from patients with resectable CRLM regarding number of lesions, size of largest lesion, occurrence of bilobar CRLM, occurrence of synchronous CRLM, location of primary tumor, previous resection of primary tumor, presence of extrahepatic disease, number of pulmonary lesions and survival (Table 1). The 1-, 3- and 5-year OS for patients with unresectable CRLM were 51\%, 9\% and 4\%, respectively.

Taking all criteria into account 25 patients (8\%) of all

Table 2 Characteristics related to inclusion and exclusion criteria as well as factors predictive of poor prognosis, for patients with unresectable CRLM

\begin{tabular}{lc}
\hline Variable & $\begin{array}{c}\text { Patients with } \\
\text { unresectable } \\
\text { CRLM, N=330 }\end{array}$ \\
\hline Inclusion criteria & $311(95 \%)$ \\
Diameter of largest CRLM <100 mm & $88(69 \%)$ \\
ECOG 0-1 & $314(99 \%)$ \\
Multifocal tumor excluded & $119(36 \%)$ \\
Primary tumor resected & $70(21 \%)$ \\
Time from resection of primary tumor $>1$ year & $279(85 \%)$ \\
Chemotherapy (for at least 2 months) & \\
Exclusion criteria & $145(44 \%)$ \\
Extrahepatic disease & $19(6 \%)$ \\
Other malignancies within the last 5 years & $1(0.03 \%)$ \\
Previous transplantation & \\
Factors predictive of poor survival & $96(56 \%)$ \\
Diameter of largest CRLM $>55$ mm & $16(12 \%)$ \\
BRAF mutation & $31(31 \%)$ \\
CEA > 80 & $44(13 \%)$ \\
Time from resection of primary tumor $>2$ years & \\
\hline Progression under chemotherapy & \\
\hline
\end{tabular}

Data presented as frequency (percent) for categorical variables. CRLM, colorectal liver metastases. patients with unresectable CRLM could have been eligible for LT. Out of the patients eligible for LT, 16 patients, $64 \%$ were alive after 1 year, 5 patients, 20\%, after 3 years and 1 patient after 5 years, $4 \%$. If considering the criteria of a time period exceeding 1 year from resection of the primary tumor, 17 patients (5\%) could have been considered for LT. Eight patients (2\%) could have been considered for LT if the four clinical factors that emerged as predictive of poor survival in the SECA 1 study were exclusion criteria; diameter of the largest tumor $\geq 55 \mathrm{~mm}$, pretransplant CEA level $>80 \mu \mathrm{g} / \mathrm{L}$, progressive disease on chemotherapy, time from resection of the primary tumor to transplant $<2$ years (9).

The most common cause for rendering patients ineligible for LT was presence of primary tumor, 211 patients (64\%). For 47 patients (22\%) presence of the primary tumor was the only cause rendering them ineligible for LT. The occurrence of pathological lymph nodes would have been cause for ineligibility in 37 patients $(11 \%)$, occurrence of lung metastases in 53 patients $(16 \%)$ and carcinosis and other extrahepatic manifestations, including local relapse in 72 patients (22\%). Progression during chemotherapy was present in 69 patients (21\%) (Table 2). One hundred and twenty-one patients (37\%) had one exclusion criterion, 157 patients (48\%) fulfilled 2 exclusion criteria and 26 patients $(8 \%)$ fulfilled 3 exclusion criteria. The median OS in patients with unresectable CRLM was 12 months (Table 1). The median OS for patients with unresectable CRLM eligible for LT was significantly higher than the OS for patients with unresectable CRLM ineligible for LT, 18 vs. 12 months, $\mathrm{P}=0.037$. The multivariate Cox regression analysis is summarized in Table 3. Eligibility for LT and left-sided primary tumor were significantly associated with favorable OS, illustrated in Figure 1.

\section{Potential donors}

Out of 1,462 analyzed contacts, i.e., possible deceased organ donors, 21 went on being actual and 462 utilized donors. Of the remaining 979 potential DBD donors, 179 were enrolled in the final analysis (Figure 2). A total of

Table 3 Prognostic features for OS in patients with unresectable CRLM

\begin{tabular}{lccc}
\hline Variable & Hazard ratio & $95 \% \mathrm{Cl}$ & $\mathrm{P}$ value \\
\hline Potential candidates for LT & 0.558 & $0.329-0.946$ & 0.030 \\
Left-sided carcinoma (hindgut origin) & 0.729 & $0.570-0.933$ & 0.012 \\
\hline
\end{tabular}

OS, overall survival; CRLM, colorectal liver metastases; LT, liver transplantation. 


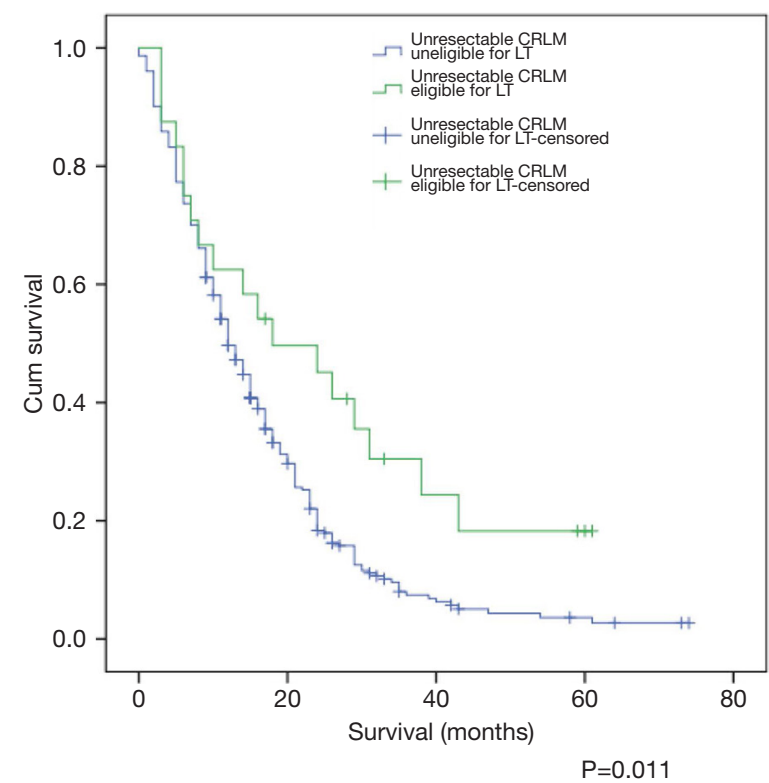

Figure 1 Overall survival in patients with unresectable CRLM depending on eligibility for LT. CRLM, colorectal liver metastases; LT, liver transplantation.

62 acceptable potential DBD donors were identified, of which 13 were eligible DBD donors, i.e. had performed/ completed diagnosis of brain death. Forty-nine of the acceptable potential DBD donors were not yet diagnosed brain dead but whose clinical conditions were so severe as to render them highly likely to shortly fulfill the criteria (Figure 2). During the study period the death on the waiting list was $2.8 \%$ and $3.2 \%$ were withdrawn from the waiting list, out of which $0.3 \%$ due to improvement.

\section{Medical contraindications}

A total of 199 medical contraindications were identified in 179 potential DBD donors. Cancer was the medical contradiction in 108 potential DBD donors $(60 \%)$, out of which the most common cancers were: blood malignancy (17\%), CRC (7\%) and prostate cancer (6\%). Eighteen potential DBD donors (10\%) had hepatitis B virus (HBV), out of which 8 potential DBD donors had a documented inactive disease (anti-HBc positive donors). Hepatitis $\mathrm{C}$ virus (HCV) was present in 38 potential DBD donors (21\%). Human immunodeficiency virus (HIV) was present in 4 cases. In total there were 40 different medical contraindications stated in the records.

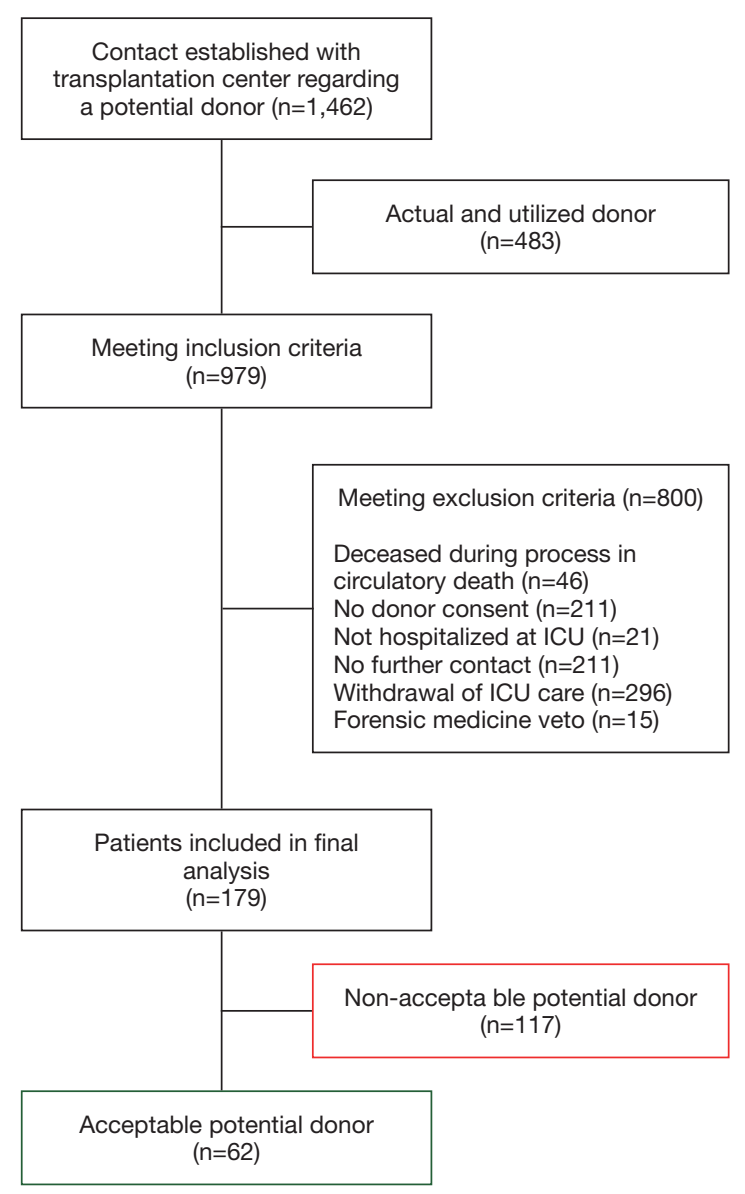

Figure 2 Flow-chart of potential DBD donors. DBD, donation after brain death.

\section{Age distribution}

Age was available in 156 of 179 potential DBD donors (87\%). Seventy-one potential DBD donors (46\%) were 65 years or younger. The median age of all potential DBD donors was 68 years. Of the acceptable potential DBD donors $48 \%$ were above 65 years of age, with a median age of 75 years. Seventeen potential DBD donors were considered too old, median age 86 , range 75-94 years, out of these 13 cases had acceptable liver function and were accepted as extended criteria donors. In 23 cases (13\%) the age was not stated.

\section{Distribution of blood groups}

The blood group was stated in 73 potential donors. Blood group A was the most frequent, 29 potential DBD donors 
(40\%) (Table 4). Blood group B, 16 potential donors (22\%), and blood group $\mathrm{AB}, 9$ potential donors (12\%), were overrepresented compared to the distribution in utilized donors and in the general population in Sweden 1986-2017, whereas blood group 0 was less frequent in potential donors compared to the general population (Table 4).

\section{Liver function}

In 179 potential DBD donors' liver function was stated in 74 cases, out of which 67 cases $(91 \%)$ had acceptable liver function. In 105 cases (59\%) the liver function was not possible to evaluate due to lack of information in the registers. A total of 113 potential DBD donors was considered unacceptable independently of liver function

Table 4 Distribution of blood groups

\begin{tabular}{lcccc}
\hline $\begin{array}{l}\text { Blood } \\
\text { group }\end{array}$ & $\begin{array}{c}\text { Number of } \\
\text { potential donors }\end{array}$ & $\begin{array}{c}\text { \% of } \\
\text { stated }\end{array}$ & $\begin{array}{c}\text { \% in utilized } \\
\text { donors }^{\mathrm{a}}\end{array}$ & $\begin{array}{c}\text { \% distribution } \\
\text { in Sweden }\end{array}$ \\
\hline Stated & 73 & 100 & & \\
A & 29 & 40 & 47 & 44 \\
B & 16 & 22 & 11 & 12 \\
AB & 9 & 12 & 5 & 6 \\
0 & 19 & 26 & 37 & 38 \\
Not stated & 106 & & & \\
\hline
\end{tabular}

a , blood groups 1986-2017 in utilized donors in the region of OFO Sweden.
(Table 5). Eleven of the 13 acceptable potential DBD donors $(85 \%)$ which were confirmed dead had an acceptable liver function. The annual range of acceptable potential DBD donors was 5 to 16 (Table 6).

A range of 1.1-3.6 acceptable potential DBD donors per million population (pmp) in the Swedish region were found during the period of 2013-2017. Compared to utilized DBD donors with an interval of 19.6-21.2 pmp, the portion of acceptable potential donors was $6-18 \%$. During the same time period a range of $0.4-3.4$ potential recipients pmp were identified in the Stockholm area, yet $25 \%$ of the included patients, discussed at MDT conference, were referred from other counties (Table 6). Fourteen out of the eligible candidates for LT (56\%) were patients referred from other counties.

\section{Discussion}

Unresectable CRLM is a condition with poor prognosis (3). Advances in chemotherapeutic treatments have prolonged survival in patients with metastatic CRC, yet the 5 -year survival is limited $(4,7,20)$. First-line chemotherapy with targeted therapies for metastatic CRC has shown a median OS of 23-30 months $(5,7,21,22)$ and approximately 12 months following second-line chemotherapy (23-25). The reported 5 -year survival of $50 \%, 60 \%$ and $83 \%$ in patients with CRLM treated with LT, reported by the SECA-studies and centers affiliated to "les Compagnons Hépato-Biliaires", by far exceed that of patients with metastatic CRC treated with chemotherapy, yet in a selected

Table 5 Potential donors, subdivided according to liver function assessment and potential recipients during the study period

\begin{tabular}{lccccccc}
\hline Variable & $2018^{\text {a }}$ & 2017 & 2016 & 2015 & 2014 & 2013 & Total \\
\hline Acceptable potential donors, in which brain death diagnosis is performed & & & & & & \\
With acceptable liver function & 1 & 3 & 4 & 2 & 1 & 0 & 11 \\
With liver function not stated & 0 & 0 & 2 & 0 & 0 & 0 & 2 \\
With unacceptable liver function & 0 & 0 & 0 & 0 & 0 & 0 & 0 \\
Acceptable potential donors, in which brain death diagnosis is not yet performed & & & & & \\
With acceptable liver function & 3 & 7 & 2 & 5 & 6 & 3 & 26 \\
With liver function not stated & 5 & 6 & 2 & 5 & 3 & 2 & 23 \\
With unacceptable liver function & 0 & 0 & 1 & 0 & 2 & 1 & 4 \\
Unacceptable potential donor & 20 & 18 & 17 & 23 & 23 & 12 & 113 \\
Potential recipients & 1 & 4 & 4 & 5 & 8 & 3 & 25 \\
\hline
\end{tabular}

${ }^{\text {a }}$, by Sep $31^{\text {st }}$. 
Table 6 Acceptable potential donors and recipients in relation to per million population

\begin{tabular}{|c|c|c|c|}
\hline Year & $\begin{array}{c}\text { Brain death } \\
\text { diagnosis } \\
\text { performed, } \\
\text { No. }\end{array}$ & $\begin{array}{l}\text { Brain death } \\
\text { diagnosis not } \\
\text { performed, } \\
\text { No. }\end{array}$ & $\begin{array}{l}\text { All potential } \\
\text { donors (brain } \\
\text { death diagnosis } \\
\text { performed), per } \\
\text { million population }\end{array}$ \\
\hline \multicolumn{4}{|c|}{ Potential donors } \\
\hline $2018^{a}$ & 1 & 8 & - \\
\hline 2017 & 3 & 13 & $3.6(0.7)$ \\
\hline 2016 & 6 & 4 & $2.2(1.3)$ \\
\hline 2015 & 2 & 10 & $2.7(0.4)$ \\
\hline 2014 & 1 & 9 & $2.2(0.2)$ \\
\hline 2013 & 0 & 5 & 1.1 \\
\hline Total & 13 & 49 & - \\
\hline \multicolumn{4}{|c|}{ Utilized donors } \\
\hline $2018^{a}$ & 52 & - & - \\
\hline 2017 & 87 & - & 19.6 \\
\hline 2016 & 93 & - & 21.2 \\
\hline 2015 & 86 & - & 19.9 \\
\hline 2014 & 85 & - & 19.9 \\
\hline 2013 & 80 & - & 19.0 \\
\hline Total & 483 & - & - \\
\hline \multicolumn{4}{|c|}{ Potential recipients (unresectable CRLM) } \\
\hline $2018^{a}$ & 1 & - & - \\
\hline 2017 & 4 & - & 1.7 \\
\hline 2016 & 4 & - & 1.7 \\
\hline 2015 & 5 & - & 2.1 \\
\hline 2014 & 8 & - & 3.4 \\
\hline 2013 & 3 & - & 1.3 \\
\hline Total & 25 & - & - \\
\hline
\end{tabular}

a, by Sep $31^{\text {st }}$. CRLM, colorectal liver metastases.

number of patients $(8,10,26)$.

In the SECA 1 study the selection criteria were broader than the following SECA 2 study $(8,10)$. From the SECA 1 trial, four clinical factors emerged as predictive of poor survival: diameter of the largest CRLM $>55 \mathrm{~mm}$, pretransplant CEA level $>80 \mu \mathrm{g} / \mathrm{L}$, progressive disease on chemotherapy and time from resection of the primary tumor to transplant $>2$ years $(8,10)$. The study by centers affiliated to "les Compagnons Hépato-Biliaires" reported a 5 -years survival of $50 \%$, after having transplanted 9 patients, 41 months after resection of the primary tumor and excluding patients with progression during chemotherapy (26).

When evaluating potential candidates for LT in a Swedish setting during a 5.5 years period, 25 patients (8\%) of all patients with unresectable CRLM could have been eligible for LT. If considering the criteria of a time period exceeding 2 years from resection of the primary tumor, 17 patients (5\%) could have been considered for LT. The number was reduced to 8 patients $(2 \%)$ if the four clinical factors that emerged as predictive of poor survival in the SECA study were taken into account (8). This is the first study, to our knowledge, to evaluate how many patients with unresectable CRLM that could fulfill the criteria for a positive outcome of LT and consequently the need for allocation of organs. The most common cause for LT ineligibility was the presence of primary tumor, 211 patients (64\%). Forty-four patients had had their primary tumor removed more than 2 years earlier and in 48 patients (15\%) the presence of a primary tumor was the only criterion rendering them ineligible for LT. The criterion of time from resection of the primary tumor has been discussed in the studies evaluating LT and is suggested to be of prognostic importance $(8,26)$. A criterion of resected primary tumor at time for inclusion could have an impact on the timing of resection of the primary tumor. It could theoretically increase the demand of early resection of the primary tumor in patients with metastatic CRC, which currently is not part of general practice in Sweden, in order to qualify for LT (27).

The selected group of patients eligible for LT, possess several positive prognostic factors and were found to have a significantly better survival compared to patients with metastatic CRC that did not fulfill the criteria for LT. Eligibility to LT was a positive prognostic factor for OS, together with the occurrence of a left-sided primary tumor. Tumor sidedness is a known prognostic factor for OS but the better survival in patients eligible for LT has not been described before and could add arguments both for and against LT as treatment alternative for patients with unresectable CRLM (28). Theoretically, the inclusion criteria for LT select a group of patients with a more favorable tumor biology and response to chemotherapy. The selected sub-group of patients eligible for LT are, their advanced malignancy aside, at comparatively good health with preserved liver function, hence would theoretically be able to sustain the injury of a marginal graft (29).

In this study a significant number of potential DBD 
donors were identified. Sixty-two of 179 potential donors included in the final analysis were found acceptable, out of which 13 were confirmed dead with positive donor consent. In relation to utilized donors today the portion of potential donors that could be used for the planned study would be 6-18\%.

In this study, only DBD was evaluated. Donation after circulatory death (DCD), with advances in organ procurement, has the potential of adding grafts to both patients already on the waiting list as well as patients with unresectable CRLM (30), without compromising the need of evaluating the use of DBD marginal grafts for unresectable CRLM. In reality, the organ shortage has already pushed the limits of marginality (30). We believe that the risk of death on the waiting list for patients with conditions, in which LT is an established treatment, is not augmented by allocating marginal grafts to patients with unresectable CRLM in a clinical trial. The allocation of using marginal grafts to patients with CRLM raises the topic and could enable studies on patients with other neoplastic indications, currently not eligible for transplantation.

The assessed risk factors defining extended criteria donors in this study were: age, liver grafts that carry a risk of transmission of disease and donors with extrahepatic malignancies.

Most of the previous studies in deceased donors considered $65-70$ years as the age cut-off beyond which the donor graft was marginal $(14,31)$. In this study 30 acceptable potential donors (48\%) were older than 65 years and the median age was 75 years. Studies evaluating graft and patient survival from younger and older donors report comparable results, and taking the limited 5 -year survival in patients with metastatic CRC into account, an older marginal graft with preserved liver function ought to be worth considering (15,31).

In this study the second most common medical contraindication was viral hepatitis. $\mathrm{HBV}$ was present in 18 potential donors $(10 \%)$, out of which 8 had an inactive disease (anti $\mathrm{HBc}$ positive). $\mathrm{HCV}$ was present in 38 potential donors (21\%). Improvements in antiviral therapies has made the contraindications of $\mathrm{HBV}$ and $\mathrm{HCV}$ relative (16,32-34). For HBV, the prophylactic therapy with vaccination, hepatitis $B$ immunoglobulin (HBIG) and nucleoside analogs have made anti-HBc grafts amenable for transplantation (16,32). In addition, the results of directacting antivirals (DAA) on HCV has the potential to expand the transplantation of $\mathrm{HCV}$ positive donor grafts to both $\mathrm{HCV}$ positive recipients and $\mathrm{HCV}$ negative recipients
$(33,35)$.

In this study the distribution of blood groups differed compared to both the general population in Sweden and to utilized donors. Blood group 0 was underrepresented suggesting that more extended criteria donors are accepted for blood group 0 due to increased waiting time (13).

The primary limitation in this study is the missing data of potential donors, which is most likely related to the early contact with transplant coordinators, before the diagnosis of brain death is established or donor consent evaluated, as many potential donors can be declined based on medical contraindications only. The lack of information about donor consent in the 49 potential DBD donors not yet confirmed dead is related to the lack of access to the donation register until the patient is confirmed dead. The missing data on potential recipients is limited but mutation status and ECOG were lacking in several potential recipients. Another limitation regarding the potential recipients is the difficulty in evaluating the number of potential recipients pmp. Twenty-six per cent of patients discussed at MDT conference at Karolinska University Hospital during the study period were referred from other counties and therefore the stated number of potential recipients pmp might in fact be slightly lower.

In conclusion, with current selection criteria a small subset of patients with unresectable CRLM could be accepted for LT. This subset of patients possesses several positive prognostic factors and have a better survival compared to patients with unresectable CRLM ineligible for LT. The use of extended criteria donors could increase today's donor pool by $6-18 \%$. This donor pool is sufficient and displays an acceptable risk-benefit ratio for patients with unresectable CRLM.

\section{Acknowledgments}

Funding: None.

\section{Footnote}

Reporting Checklist: The authors have completed the STROBE reporting checklist. available at https://hbsn. amegroups.com/article/view/10.21037/hbsn.2020.03.10/rc

Data Sharing Statement: Available at https://hbsn. amegroups.com/article/view/10.21037/hbsn.2020.03.10/dss

Conflicts of Interest: All authors have completed the 
ICMJE uniform disclosure form (available at https://hbsn. amegroups.com/article/view/10.21037/hbsn.2020.03.10/coif). The authors have no conflicts of interest to declare.

Ethical Statement: The authors are accountable for all aspects of the work in ensuring that questions related to the accuracy or integrity of any part of the work are appropriately investigated and resolved. The study was conducted in accordance with the Declaration of Helsinki (as revised in 2013). The study was approved by the Regional Ethics Committee in Stockholm (NO 2018/1261-31).

Open Access Statement: This is an Open Access article distributed in accordance with the Creative Commons Attribution-NonCommercial-NoDerivs 4.0 International License (CC BY-NC-ND 4.0), which permits the noncommercial replication and distribution of the article with the strict proviso that no changes or edits are made and the original work is properly cited (including links to both the formal publication through the relevant DOI and the license). See: https://creativecommons.org/licenses/by-nc-nd/4.0/.

\section{References}

1. Kopetz S, Chang GJ, Overman MJ, et al. Improved survival in metastatic colorectal cancer is associated with adoption of hepatic resection and improved chemotherapy. J Clin Oncol 2009;27:3677-83.

2. Kanas GP, Taylor A, Primrose JN, et al. Survival after liver resection in metastatic colorectal cancer: review and meta-analysis of prognostic factors. Clin Epidemiol 2012;4:283-301.

3. Van Cutsem E, Kohne CH, Hitre E, et al. Cetuximab and chemotherapy as initial treatment for metastatic colorectal cancer. N Engl J Med 2009;360:1408-17.

4. Masi G, Vasile E, Loupakis F, et al. Randomized trial of two induction chemotherapy regimens in metastatic colorectal cancer: an updated analysis. J Natl Cancer Inst 2011;103:21-30.

5. Boeckx N, Koukakis R, Op de Beeck K, et al. Primary tumor sidedness has an impact on prognosis and treatment outcome in metastatic colorectal cancer: results from two randomized first-line panitumumab studies. Ann Oncol 2017;28:1862-8.

6. Basso M, Dadduzio V, Ardito F, et al. Conversion Chemotherapy for Technically Unresectable Colorectal Liver Metastases: A Retrospective, STROBE-Compliant, Single-Center Study Comparing Chemotherapy Alone and Combination Chemotherapy With Cetuximab or Bevacizumab. Medicine (Baltimore) 2016;95:e3722.

7. Van Cutsem E, Kohne CH, Lang I, et al. Cetuximab plus irinotecan, fluorouracil, and leucovorin as first-line treatment for metastatic colorectal cancer: updated analysis of overall survival according to tumor KRAS and BRAF mutation status. J Clin Oncol 2011;29:2011-9.

8. Dueland S, Syversveen T, Solheim JM, et al. Survival Following Liver Transplantation for Patients With Nonresectable Liver-only Colorectal Metastases. Ann Surg 2020;271:212-8.

9. Dueland S, Guren TK, Hagness M, et al. Chemotherapy or liver transplantation for nonresectable liver metastases from colorectal cancer? Ann Surg 2015;261:956-60.

10. Hagness M, Foss A, Line PD, et al. Liver transplantation for nonresectable liver metastases from colorectal cancer. Ann Surg 2013;257:800-6.

11. Olsson L. Epidemiologi. In: Rci S. editor. Tjock- och ändtarmscancer - Nationellt vårdprogram [Internet]: Cancercentrum.se, 2016:15.

12. Sandström $P$, Glimelius B, Samuelsson $M$, et al. Behandling av kolorektala levermetastaser (KRLM). In: Rci S. editor. Tjock- och ändtarmscancer - Nationellt vårdprogram [Internet]: Cancercentrum.se, 2016:147-8.

13. Melum E. The Nordic Liver Transplant Registry - Annual report 2017. Scandiatransplant. Available online: http:// www.scandiatransplant.org/members/nltr/TheNordicLi verTransplantRegistryANNUALREPORT2017.pdf/at_ download/file. Accessed June 2018.

14. Ghinolfi D, Lai Q, Pezzati D, et al. Use of Elderly Donors in Liver Transplantation: A Paired-match Analysis at a Single Center. Ann Surg 2018;268:325-31.

15. Westerkamp AC, Korkmaz KS, Bottema JT, et al. Elderly donor liver grafts are not associated with a higher incidence of biliary complications after liver transplantation: results of a national multicenter study. Clin Transplant 2015;29:636-43.

16. Loggi E, Conti F, Cucchetti A, et al. Liver grafts from hepatitis $B$ surface antigen-positive donors: A review of the literature. World J Gastroenterol 2016;22:8010-6.

17. Van Cutsem E, Cervantes A, Adam R, et al. ESMO consensus guidelines for the management of patients with metastatic colorectal cancer. Ann Oncol 2016;27:1386-422.

18. Dueland S, Foss A, Solheim JM, et al. Survival following liver transplantation for liver-only colorectal metastases compared with hepatocellular carcinoma. Br J Surg 2018;105:736-42.

19. Dominguez-Gil B, Delmonico FL, Shaheen FA, et al. 
The critical pathway for deceased donation: reportable uniformity in the approach to deceased donation. Transpl Int 2011;24:373-8.

20. Ye LC, Liu TS, Ren L, et al. Randomized controlled trial of cetuximab plus chemotherapy for patients with KRAS wild-type unresectable colorectal liver-limited metastases. J Clin Oncol 2013;31:1931-8.

21. Douillard JY, Siena S, Cassidy J, et al. Randomized, phase III trial of panitumumab with infusional fluorouracil, leucovorin, and oxaliplatin (FOLFOX4) versus FOLFOX4 alone as first-line treatment in patients with previously untreated metastatic colorectal cancer: the PRIME study. J Clin Oncol 2010;28:4697-705.

22. Tveit KM, Guren T, Glimelius B, et al. Phase III trial of cetuximab with continuous or intermittent fluorouracil, leucovorin, and oxaliplatin (Nordic FLOX) versus FLOX alone in first-line treatment of metastatic colorectal cancer: the NORDIC-VII study. J Clin Oncol 2012;30:1755-62.

23. Sobrero AF, Maurel J, Fehrenbacher L, et al. EPIC: phase III trial of cetuximab plus irinotecan after fluoropyrimidine and oxaliplatin failure in patients with metastatic colorectal cancer. J Clin Oncol 2008;26:2311-9.

24. Hurwitz HI, Tebbutt NC, Kabbinavar F, et al. Efficacy and safety of bevacizumab in metastatic colorectal cancer: pooled analysis from seven randomized controlled trials. Oncologist 2013;18:1004-12.

25. Peeters M, Price TJ, Cervantes A, et al. Randomized phase III study of panitumumab with fluorouracil, leucovorin, and irinotecan (FOLFIRI) compared with FOLFIRI alone as second-line treatment in patients with metastatic colorectal cancer. J Clin Oncol 2010;28:4706-13.

26. Toso C, Pinto Marques H, Andres A, et al. Liver transplantation for colorectal liver metastasis: Survival without recurrence can be achieved. Liver Transpl 2017;23:1073-6.

27. Valdimarsson VT, Syk I, Lindell G, et al. Outcomes of

Cite this article as: Villard C, Westman J, Frank J, Jynge O, Sparrelid E, Jorns C. The potential use of extended criteria donors and eligible recipients in liver transplantation for unresectable colorectal liver metastases in Central Sweden. HepatoBiliary Surg Nutr 2021;10(4):476-485. doi: 10.21037/ hbsn.2020.03.10 liver-first strategy and classical strategy for synchronous colorectal liver metastases in Sweden. HPB (Oxford) 2018;20:441-7.

28. Petrelli F, Tomasello G, Borgonovo K, et al. Prognostic Survival Associated With Left-Sided vs Right-Sided Colon Cancer: A Systematic Review and Meta-analysis. JAMA Oncol 2017;3:211-9.

29. Dutkowski P, Oberkofler CE, Slankamenac K, et al. Are there better guidelines for allocation in liver transplantation? A novel score targeting justice and utility in the model for end-stage liver disease era. Ann Surg 2011;254:745-53; discussion 753.

30. Bodzin AS, Baker TB. Liver Transplantation Today: Where We Are Now and Where We Are Going. Liver Transpl 2018;24:1470-5.

31. Kim DY, Moon J, Island ER, et al. Liver transplantation using elderly donors: a risk factor analysis. Clin Transplant 2011;25:270-6.

32. Skagen CL, Jou JH, Said A. Risk of de novo hepatitis in liver recipients from hepatitis-B core antibodypositive grafts - a systematic analysis. Clin Transplant 2011;25:E243-9.

33. Ferrarese A, Germani G, Gambato M, et al. Hepatitis $\mathrm{C}$ virus related cirrhosis decreased as indication to liver transplantation since the introduction of direct-acting antivirals: A single-center study. World J Gastroenterol 2018;24:4403-11.

34. Bonacci M, Londono MC, Esforzado N, et al. Antiviral treatment with sofosbuvir and simeprevir in a kidney transplant recipient with $\mathrm{HCV}$-decompensated cirrhosis: viral eradication and removal from the liver transplant waiting list. Transpl Int 2015;28:1345-9.

35. Perricone G, Duvoux C, Berenguer M, et al. Delisting $\mathrm{HCV}$-infected liver transplant candidates who improved after viral eradication: Outcome 2 years after delisting. Liver Int 2018;38:2170-7. 


\section{Supplementary}

Table S1 Criteria used in order to identify eligible candidates for LT

Inclusion criteria

Primary tumour removed with an R0-resection, and histologically verified as adenocarcinoma from colon or rectum

No signs of extra hepatic metastatic disease or local recurrence according to MRI and CT of thorax/abdomen and/or whole-body PET/

CT scan

ECOG performance status of 0 or 1

Received at least 2 months of chemotherapy with no signs of progressive disease

Time lapse of one year or more from the initial CRC diagnosis

Before start of chemotherapy no lesion should be larger than $100 \mathrm{~mm}$

Exclusion criteria

Evidence of extra hepatic disease by PET-CT or CT-thorax/abdomen

Pregnant or breast-feeding patients

Other malignancies the last 5 years, except CRC and low risk tumors such as basaliomas

Any extra hepatic metastases ever. Pulmonary lesions: no more than 2 lesions smaller than $5 \mathrm{~mm}$ or 1 lesion larger than $5 \mathrm{~mm}$ without pathological signal on PET-thorax

B-RAF mutation in the primary tumour

Previous organ transplant

LT, liver transplantation.

Table 2 Criteria used in order to identify eligible donors

Inclusion criteria

Donors with a history of malignancy with a low to intermediate risk of transmission (EDQM)

Donors with a present malignancy with a low to intermediate risk of transmission (EDQM)

Donors with recent drug misuse

Donors with active hepatitis $C$ and with preserved liver function

Donors with positive hepatitis B core antibody and preserved liver function

Exclusion criteria

Donors with a current malignancy or history of malignancy with a high risk of transmission (EDQM)

Donors with positive hepatitis B surface antibody

Circulatory death

No donor consent

Not hospitalized at ICU

HIV positive

Discontinued contact with OPO

Withdrawal of ICU care by physician or on request by relatives

Donors with a history of malignancy with high to unacceptable risk of transmission (EDQM)

Donors with a present malignancy with a high to unacceptable risk of transmission (EDQM)

EDQM, the European Committee Guide to the quality and safety of organs for transplantation; ICU, intensive care unit; OPO, organ procurement organization. 